Article

\title{
The Impact of Legislation on Sustainability of Farm Forests in Kenya: The Case of Lugari Sub-County in Kakamega County, Kenya
}

\author{
Sylvester Ngome Chisika ${ }^{1}$, Juneyoung Park ${ }^{2}$ and Chunho Yeom ${ }^{1, *(1)}$ \\ 1 International School of Urban Sciences, University of Seoul, Seoul 02504, Korea; sylvesterchizika@gmail.com \\ 2 Department of Transportation \& Logistics Engineering, Hanyang University, Ansan-si 15588, Korea; \\ juneyoung@hanyang.ac.kr \\ * Correspondence: chunhoy7@uos.ac.kr
}

Received: 22 October 2019; Accepted: 16 December 2019; Published: 18 December 2019

check for updates

\begin{abstract}
This study analyses the effects of the Agriculture (Farm Forestry Rules) of 2009 on Trees on Farms (ToFs) in Lugari sub-county in Kenya. Using existing literature, secondary and primary data sources from online surveys, the authors evaluated the current status of farm forests in order to determine the impact of these rules on respondents from three randomly selected income-expenditure groups through online surveys. Case results substantiate that between the years 2009-2019, ToFs generated social, economic, and environmental benefits amongst landowners surveyed. Moreover, online survey results indicate that young people in the age bracket 18-35 years are increasingly adopting farm forestry contrary to long-held beliefs in the country. However, due to the unpopularity of the $10 \%$ rule amongst surveyed income-expenditure groups, and challenges experienced by ToFs owners, this paper concludes that the observed impacts may not be necessary as a response to the $10 \%$ rule. Besides addressing the existing inconsistencies, this paper recommends full implementation by transcribing the rules in other languages, developing inventory protocols for ToFs, and awareness creation on the rules in order to register an impact.
\end{abstract}

Keywords: trees on farms; farm forestry rules; agricultural land; forest products; livelihoods

\section{Introduction}

Farm forests are increasingly gaining recognition amongst landowners. These forests, even though defined variously, in this paper they are defined as trees, whether occurring singly, in rows, lines, boundaries or woodlots or private forests and are often found in agricultural lands, many agroforestry systems, and home-gardens and roadside. Owners of farm forests are now organizing themselves into producer groups and partnerships in order to maximize benefits. Nonetheless, there are considerable policy obstacles that should overcome if farms are to produce products of the quality and quantity sought by markets and enhance incomes for farm families [1]. It is estimated that between 500 million and one billion smallholder farmers worldwide, grow farm trees, or manage remnant forests for subsistence and income [2]. Africa, Asia, Latin America, and Oceania have the highest potential for tree domestication towards sustainable development [3].

In Kenya, it is estimated that the amount of woody biomass material on farmlands is more than that of indigenous and plantations forests combined [4]. However, the commercial value of farm-grown trees has remained unproven owing to huge market incentives in the past to access bulk logs from government plantation and indigenous forests and lack of inventory protocols for Trees on Farms (ToFs) [5,6]. To date, issues of farm forestry are deeply entrenched in the 2010 constitution and other forest policy documents, however, there is still a scarcity of information on their impact on ToFs. 
However, the demand for tree products is increasing as the population grows [6]. It is, therefore, imperative to conduct studies on how to improve forest management policies in a manner that will ensure that farm forests farms guarantee stability in the supply of forest goods for present and future generations. Thus, this study is paramount for three reasons. First, there appears to be a considerable gap between farm forestry policy prescriptions and implementation outcomes. Secondly, studies on farm forestry have majorly focused on factors affecting its adoption, but policy factors are rarely exhaustively discussed. Thirdly, most studies have been conducted only through face to face interviews and survey questionnaires that are filled on-site. These methods are quite slow, costly and are prone to the "interviewer's effect," which could result in research bias.

This paper explores the advantages of an online survey through Google forms shared through Facebook over face to face interviews and questionnaires in the case of ToFs in Lugari sub-county within Kakamega County in Kenya to document the impact of the 10\% Agriculture (Farm Forestry) Rules of 2009 in Kenya. Towards this objective, the study compares the impacts of the rule on three household income expenditure groups (low, middle, and high incomes) identified on Facebook in the period 2010-2019 to explore the current status. In order to adequately respond to the research objective, this paper will first review the policy issues affecting ToFs management in Kenya from the perspective of sustainable development before examining a case study to provide the study implications of this paper.

\subsection{The Status of ToFs in Kenya}

Kenya endows with a wide range of forest ecosystems ranging from montane rainforests, savannah woodlands, dry forests, and coastal forests and mangroves. The current forest cover of $7.2 \%$ of the land area of the country is still below the constitutional requirement of $10 \%$ [6]. These forests have high species richness and endemism, which has made the country classified as megadiverse. These forests rank high as the country's natural asset, due to their environmental, life-supporting functions, and the provision of various goods and services for present and future generations [7].

Farm forests form suitable smallholder land-use options in the country as they provide subsistence and commercial values with some tree-growing practices showing close relation to the presence of both rural and urban markets for tree-based goods [8]. It is due to these benefits that the Government of Kenya, over the last decade, has sought to promote land-use systems integrating trees with crops and/or livestock to reduce deforestation, improve soil, and water conservation [9].

Farmlands in the country cover an area of 9,939,255 ha and are currently estimated to have an average wood biomass of $17.58 \mathrm{~m}^{3}$ per ha. Moreover, trees on farms manage to meet household needs and for commercial purposes. Farm forests are believed to have a relatively short investment time horizon, and farmers end up harvesting their tree at an average age of 8 years. By application of forests normalization principle where the allowable cut is equivalent to trees in the oldest age class, out of the 9,939,255 ha of trees about 1,242,407 ha in the 8-year age, the class is harvested annually [6]. However, MENR reports that KFS record on quantities of timber demanded is based on round wood sales from public forests, and quantities reported in-transit permits from community forests and farmlands [6]. The report claims that this method does not capture households' consumption quantities sourced from their lands, leaving out wood acquired by sawmills from the community and private forests and those from farms.

Moreover, even though farm forestry is affected by many factors, the practice has moved from conventional resource extraction to planting in compounds, boundaries, and as windbreakers, intercropping and lately intensively managed mono-cropping in the form of woodlots for commercial purpose. Interestingly, at present, tree cover on farms is increasing, especially in more densely populated areas with higher agricultural potential [7]. This paper observes that this demonstrates that farmers recognize the benefits of a tree growing in improving land productivity. Besides, while challenges in tree growing are higher in the lower rainfall areas, a variety of species have the potential to make tree growing in these areas profitable [7]. 
Two national organizations promote the management of ToFs in Kenya [10]. They include Farm Forestry Smallholder Producers Association of Kenya (FF SPAK) and Kenya Tree Growers Association (KETGA). FF SPAK is an umbrella organization based in Nairobi and working with farmer groups to promote the interests of farm forestry smallholders. It was registered in the year 2013, and it has an office in Nairobi and Nakuru. Its mission is to strengthen the capacity of member organizations to enable farm forestry producers to improve their livelihoods. FF SPAK affiliate association members include Western Tree Planters Association (WTPA), Meru Farm Forestry Producers Association (MEFFPA), and Kisii Tree Planters Association (KTPA), South Coast Forest Owners Association (SCOFOA), Central Highlands Tree Growers Association (CHTGA), Community Food and Environment Group (COFEG), Nakuru Smallholder Timber Association (NASTA), and North Coast Farm Forestry Association (NCFFA). FFSPAK membership is open to any registered association/cooperative whose activities are related to farm forestry. A remarkable association/cooperative makes an application to become a member, and if approved, the member pays off registration and annual subscription fee as approved by the FF SPAK constitution.

In other parts of the country, farm forestry continues to grow despite challenges. Research reports based on face to face interviews and survey questionnaires indicate an increasing adoption of farm forestry in Tarakwa location in Uasin Gishu County for timber production and other products [11]. The study identifies diminishing markets for farm forestry products, limited land sizes, climate variability, pests and diseases, and seedlings unavailability as crucial challenges affecting ToFs. Wafuke, through survey questionnaires, observes an increasing adoption of agroforestry technologies in the Nzoia sub-location in the Lugari sub-county within western Kenya [12]. Similarly, Sikuku et al., through survey questionnaires, show the increasing adoption of farm forestry in Lugari Ward within the Lugari sub-county in Kenya [13]. The study enumerates some factors affecting its adoption, but policy factors, such as the influence of Farm Forestry Rules of 2009 are not highlighted amongst the factors affecting farm forestry development. However, Sikuku et al. is rather explicit and recommends institutional support through incentives, such as technical advice, tree insurance policies, and credit facilities [13]. These case study outcomes may offer valuable lessons on understanding the impact of the farm forestry rules of 2009 on the current status of ToFs in the study area.

\subsection{Forest Policy and ToFs Management Practices in Kenya}

Several legal and policy documents guide ToFs establishment and harvesting in Kenya. They are quite progressive, aligned to the constitution of 2010, and have resulted in the establishment of critical institutions, such as Kenya Forest Service (KFS), amongst others that are now steering the country towards sustainable forest management. Unfortunately, this paper submits that their full implementation may be affected by definitional challenges on the terms forest cover and tree cover, as written in these policy documents. According to the Forest Conservation and Management Act, 2016, a forest refers to land which is declared or registered as a forest or woody vegetation growing nearby in an area of over 0.5 ha. MENR has also criticized this definition as vague and subject to various interpretations because it does not specify the height of trees and the size of tree canopy [6]. Further, MENR reported that there are no systemic data collection protocols to help in assessing tree cover in the country, and thus, monitor the country's performance towards achieving the $10 \%$ target set by the constitution [6]. This paper reports that these definitional challenges are bound to affect the implementation of the farm forestry rules as well because these rules emanate from the mentioned policy documents.

Nonetheless, a review of practices resulting from ToFs policy implementation indicates there are diverse practices and livelihood outcomes, but focusing on the specific impacts of policies remains limited. For instance, face to face interview results indicates that innovative farmers are developing silvicultural methods that fit their biophysical and socio-economic conditions. Kenyan farmers in one locality close to Mount Kenya have successfully grown straight Cordia abyssinica, a high-value indigenous hardwood species that naturally grow twisted, by training and supporting it with less 
valuable, but straight-stemmed tree species. Also, in the same region, it is not uncommon to find up to 19 different tree species on one farm. In a face to face survey conducted around eastern Mount Kenya, approximately 200 different tree species were identified on farms. Fortunately, the government, through Kenya Forest Service and other stakeholders, has prepared several tree-planting guidelines, which mean to assist ToFs growers during species choice. These tree-planting manuals are available online, and they range from Eucalyptus spp. guidelines of 2009 to planting guidelines for high-value indigenous tree species that have been over-harvested in the wilderness, such as sandalwood. Researchers report that sandalwood has been exploited for over 5000 years in many countries for sandalwood oil, due to over-exploitation, which entails uprooting the whole tree, harvesting of sandalwood in Kenya was put under Presidential ban for five years with effect from the year 2007 [14]. According to the Business Daily Newspaper of 3rd October 2016, sandalwood tree exploits for the extraction of oil used as a perfume with a liter fetching up to US\$2410 in the international market, while the bark of the tree contains health benefits. Further, the newspaper reports that farmers are allowed to grow sandalwood on their farms, but they must first acquire a permit from Kenya Forestry Research Institute (KEFRI), Kenya Wildlife Service (KWS), and Kenya Forest Service (KFS). In this paper, the authors submit that even though government regulation on sandalwood is appropriate for purposes of sustainability, the various requirements from the three government agencies may be a disincentive for adoption by farmers. Besides, the species is protected under the Convention on International Trade in Endangered Species (CITES) appendix II. However, in general, there is a strong need for the farmer to farmer extension and capacity building for farmers and extension staff in tree selection, management, and marketing in order to register a more significant impact from ToFs.

\section{Methodology}

The objective of this study is to document the impacts of the Agriculture (Farm Forestry) Rules of 2019 on the management of Tree on Farms using the case of the Lugari sub-county of Kenya. In order to address this research objective, the authors asked three research questions within the conceptual framework in Figure 1. From Figure 1, implementation of policies, legislations, and institutional frameworks, such as the farm forestry rules, 2009, leads sustainable management ToFs. However, in some cases, the success of this relationship may be intervened by other community factors and stakeholders which impacts on awareness of the importance of ToFs and their sustainability. The authors asked the following questions. Firstly, what are the respondents' characteristics in the Lugari sub-county? Secondly, what are the impacts of the farm forestry rules of 2009 on the establishment and harvesting of ToFs on agricultural land in the Lugari sub-county in the period 2010-2019? Thirdly, what are the challenges of implementing the farm forestry rules of 2009 in the Lugari sub-county?

Unlike other already highlighted research reports which used face to face interviews and on-site survey questionnaires, in this study, primary data was collected using an online survey method that combined the use of Facebook and Google forms. A survey questionnaire was designed using Google forms and shared to an existing Facebook group composed of 60 participants from the six administrative wards of the study area by copying and pasting the questionnaire link into the group chat wall. By the end of the data collection period, up-to 27 random responses from participants (aged 18 years and above) from the group had responded to the survey between 8th to 10th September 2019 and were used as the source of primary data. The data include the gender of respondents, number/area of trees planted/harvested, number of inspection visits by the inspector, number of compliance certificates issued under the rule, number of harvesting permits issued, the number of tree damage cases, and the proportion of improved income for the landowner. An online survey questionnaire was the most appropriate for this study because it is cost-effective, reduces study bias, due to the "interviewer's effect," and has the advantages of shortening the research duration through the possibility of getting instant responses. Moreover, a recent study by USIU (2018) indicates that 
a majority of Kenyans were now accessing the internet, and therefore, online survey was the most feasible method of collecting data.

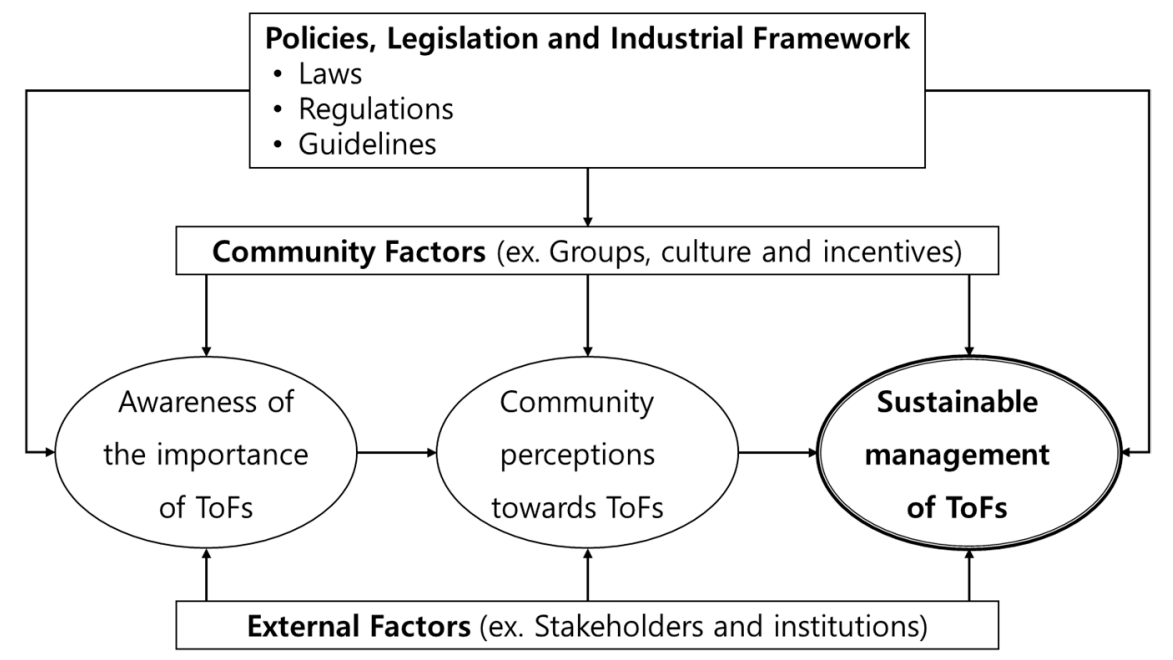

Figure 1. Trees on Farms (ToFs) and their potential to address livelihood issues (source: Reference [14]).

Secondary qualitative data collection entailed an in-depth document review targeting the Constitution of Kenya, 2010, the Forest Conservation and Management Act, 2016, the Environment Management and Coordination Act, 1999, the Climate Change Act, 2016, the Agriculture (Farm Forestry) Rules, 2009, and the draft forest policy 2014. The review entailed determining whether these policy documents were in harmony with the $10 \%$ rule or not.

Obtained results were later exported to an Excel spreadsheet and classified into three income-expenditure groups, as suggested by World Bank [15] and Jolliffe and Prydz [16]. People with the expenditure of less than $\$ 1.90$ per day is rated as a low-income group. In contrast, those with $\$ 1.91$ to $\$ 5.50$ are rated as a middle-income group, while those with expenditure above $\$ 5.5$ per day are regarded as a high-income group. In this study, these daily expenditure bands were converted to monthly (30 days) expenditure profiles to result into low (0-\$29), middle (\$30-\$145), and high (>\$146). Evaluation of responses through income-expenditure bands was a preferable method for this study because it is generally assumed that income levels determine quantities of wood consumed where higher levels of incomes result in high demand for goods and services, including forest products from ToFs [6].

Later, quantitative data was analyzed using Microsoft Excel software to generate the descriptive statistics and visualizations used in this study. The impacts of the Farm Forestry Rule of 2009 were analyzed by examining the implementation of its objectives as suggested in previous research from the perspective of sustainable development in order to draw the study conclusion [17].

\section{Case Study: Lugari Sub-County}

Lugari sub-county was carved out of the then larger Kakamega district in 1998. It was one of the eight (8) districts in the former Western province. It borders Nandi County to the south, Bungoma County to the west, Uasin Gishu County to the east, and Trans-Nzoia County to the north. It lies between longitude $34^{\circ} 28^{\prime}$ and $35^{\circ}$ East and between latitude $0^{\circ} 25^{\prime}$ and ten north of the equator [18].

It has an area of $367 \mathrm{~km}^{2}$, with 20 village units and 43 community areas, as shown in Table 1. The population of the Lugari sub-county is 215,920. Currently, the Lugari sub-county is one of the administrative units that constitute Kakamega County in western Kenya. It is a cosmopolitan area hosting more than ten tribes of Kenyans who are primarily farmers. Most people keep livestock, as well as grow crops for livelihood support. The average farm size 10 ha. Principal food crops include maize, beans, sweet potatoes, cassava, and sorghum. Cash crops include coffee, sunflower, 
sugarcane, bananas, passion, fruits, and mangoes. The principal livestock kept are dairy cows for milk production - which plays an essential part as food supplements and for household income [18]. The sub-county lies between altitudes $1300 \mathrm{~m}$ and $1800 \mathrm{~m}$ above sea level. It is hilly and rocky towards the east and gradually falls into a plain as it progresses to the south.

Table 1. Administrative units of Lugari sub-county.

\begin{tabular}{cccc}
\hline Ward & Area $\mathbf{( k m}^{\mathbf{2}} \mathbf{)}$ & No. of Village Units & No. of Community Areas \\
\hline Lumakanda & 59.0 & 4 & 8 \\
Mautuma & 83.8 & 3 & 7 \\
Lugari & 81.3 & 3 & 7 \\
Chekalini & 41.7 & 2 & 4 \\
Lwandeti & 44.2 & 4 & 8 \\
Chevaywa & 57.0 & 4 & 9 \\
Total & $\mathbf{3 6 7 . 0}$ & $\mathbf{2 0}$ & $\mathbf{4 3}$ \\
\hline
\end{tabular}

Source: The Kakamega County Integrated Development Plan (2018-2022).

Generally, the climate and rainfall patterns are of an equatorial type. Temperatures vary between $6^{\circ} \mathrm{C}$ and $23^{\circ} \mathrm{C}$ in the high altitude areas and between $18^{\circ} \mathrm{C}$ and $24^{\circ} \mathrm{C}$ in low altitude areas. The rainfall pattern is bimodal with long rains occurring from March to August, while short rains are from October to November. The average annual rainfall is between $1000 \mathrm{~mm}$ and $1600 \mathrm{~mm}$ [18]. The sub-county is endowed with fertile soils for crop production and has three state forest plantation blocks. These include Nzoia, Turbo, and Lugari blocks mostly composed of Pinus patula, Cuppresus Lusitanica, Eucalyptus spp. and Wattle trees. The sub-county has two major rivers. River Nzoia originates from the Cherangani Hills in Trans-Nzoia County; it forms the northern part of the boundary with Bungoma County [18]. The geographical and administrative information of the Lugari sub-county is presented in Table 1, and the map in Figure 2.

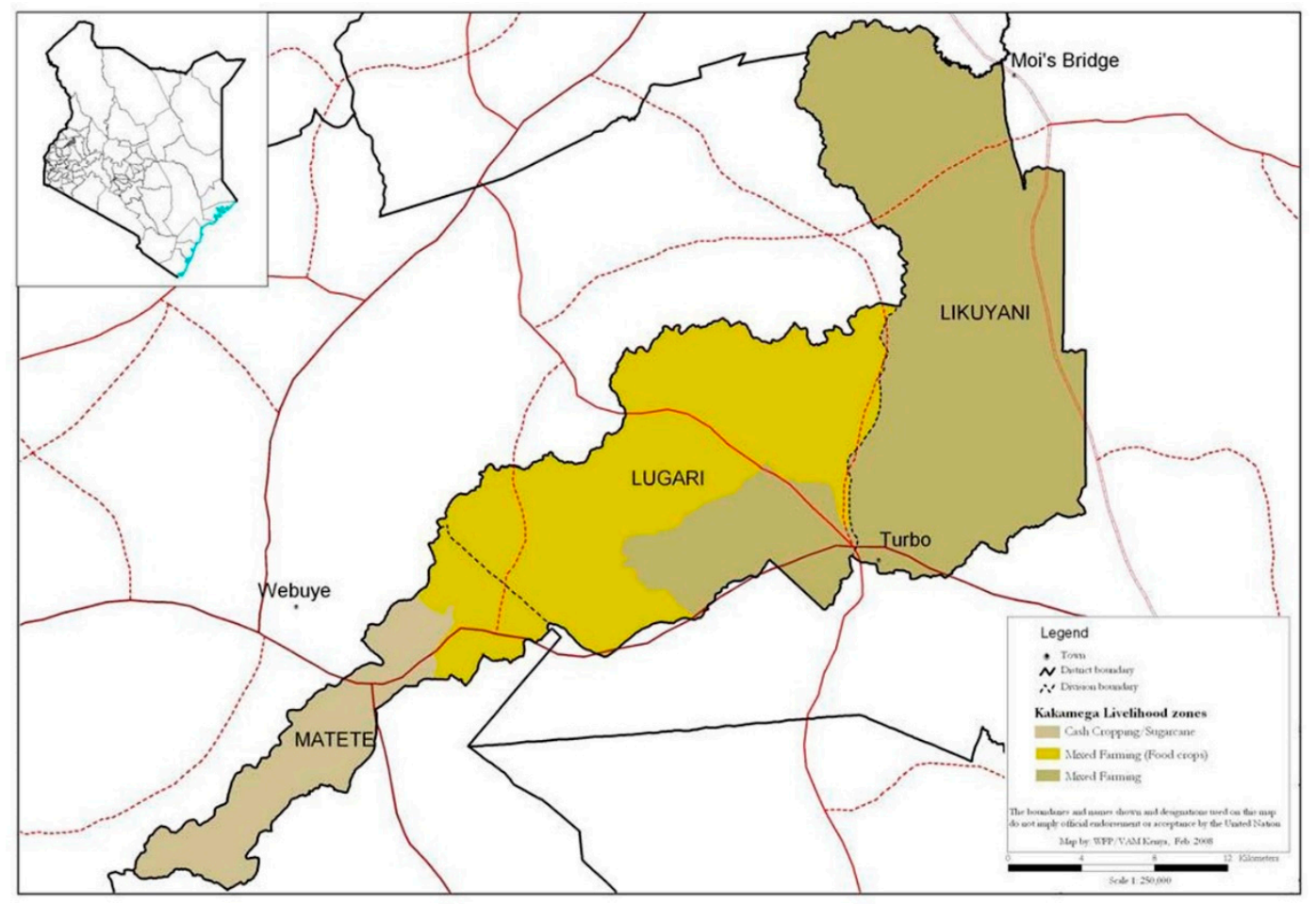

Figure 2. Map of Lugari sub-county (source: Reference [19]). 


\subsection{General Characteristics of Respondents}

Overall, there were more male respondents $(88.9 \%)$ compared to females $(11.1 \%)$. Moreover, there were $77.8 \%$ of respondents in the 18-35 year age bracket followed by $22.2 \%$ in the $36-60$ year age bracket and $0 \%$ in the $60+$ years age bracket. On education status, results indicate that overall, there were $88.9 \%$ of respondents with post-secondary education, $7.4 \%$ with secondary school qualification, and $3.7 \%$ of respondents with primary school education status. Besides, overall, $55.6 \%$ of respondents belong to the high-income expenditure band (US\$146 and above), the remaining $44.4 \%$ of respondents belonged to the US\$30-145 income-expenditure band and none in the US\$0-29 band. The general characteristic of respondents is presented in Table 2.

Table 2. General characteristic of respondents.

\begin{tabular}{cccc}
\hline & Category & Frequency & Percent (\%) \\
\hline \multirow{3}{*}{ Gender } & Male & 24 & 88.9 \\
& Female & 3 & 11.1 \\
& Prefer not to say & 0 & 0 \\
& Total & 27 & 100 \\
\hline \multirow{4}{*}{ Age bracket (years) } & $18-35$ & 21 & 77.8 \\
& $36-60$ & 6 & 22.2 \\
& $60+$ & 0 & 0 \\
Education status & Total & 27 & 100 \\
& Primary & 1 & 3.7 \\
& Secondary & 2 & 7.4 \\
& Post-secondary & 24 & 88.9 \\
& Total & 27 & 100 \\
\hline \multirow{3}{*}{ Expenditure (US\$) } & $0-29$ & 0 & 0 \\
& $30-145$ & 12 & 44.4 \\
& 146 and above & 15 & 55.6 \\
& Total & 27 & 100 \\
\hline
\end{tabular}

\subsection{The Impacts of the Farm Forestry Rules of 2009 in the Period 2010-2019}

Results indicate that ToFs have had positive social, economic, and environmental impacts on respondents. Results indicate that there were no respondents in the low-income category of 0-29 (US\$) average monthly expenditure as presented in Figure 3.

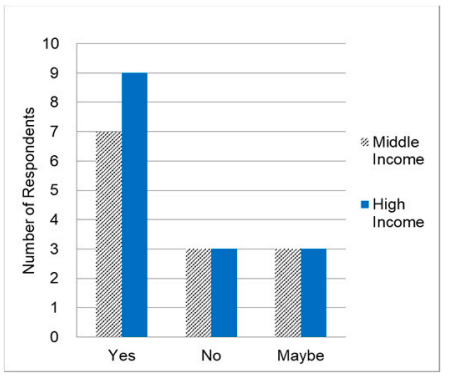

(a)

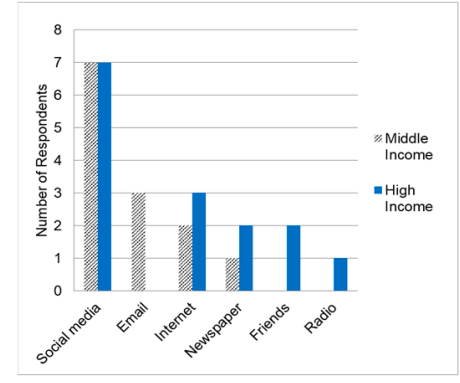

(b)

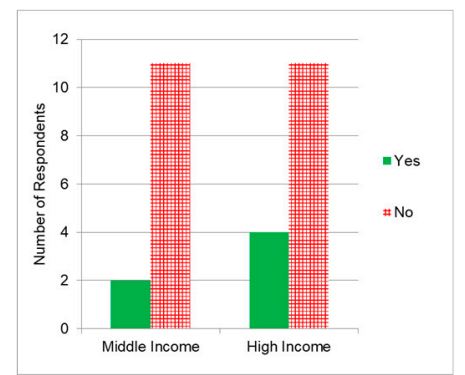

(C)

Figure 3. Responses separated by income groups: (a) Awareness about the rules; (b) channel of communication on the rules; (c) Self-help group affiliation, due to rule implementation.

Moreover, overall, results indicate that $55.6 \%$ of respondents had heard about the Farm Forestry Rules, 2009, with $37 \%$ of respondents claiming to have heard about the rules before the year 2009 against 33.3\% who heard about the rules between the years 2009-2015. Around 52\% heard about these rules via social media, while $63 \%$ would prefer to be contacted again about the rules on social media. 
Approximately $44 \%$ understand the rules. $67 \%$ of the nine respondents acknowledge that the 2009 rules are highly complex and technical, and therefore, they should be simplified in other languages. Interestingly, around $93 \%$ of all respondents prefer having the rules written in English, indicating that this sample was drawn from a group of relatively educated respondents.

Results also indicate that around $78 \%$ of respondents do not belong to a tree growers' self-help group, while around $22 \%$ are members of a self-help group that deals exclusively with tree growing. Respondents in groups indicate that groups were formed in 2003, 2016, and 2017. Moreover, around $43 \%$ of 7 respondents attend group meetings once after six months, while around $14 \%$ attend the meeting on a monthly and weekly basis. Unfortunately, for those respondents not in groups, they have indicated that no one has contacted them on awareness of such groups.

More people were establishing 1-100 and 401+ ToFs between the years 2009-2019 in the middle and high-income groups, as illustrated in Figure 4a. Overall, around $61 \%$ of respondents have planted Eucalyptus spp. On their farms, followed by Grevillea (25\%), Cypress (11\%), and Jacaranda spp. (3\%).Eucalyptus spp. Is favored because of its multiple uses and fast-growing characteristics. Line planting practice accounted for $42.9 \%$ of respondents, Boundary planting $(25 \%)$, and woodlot $(21.4 \%)$.

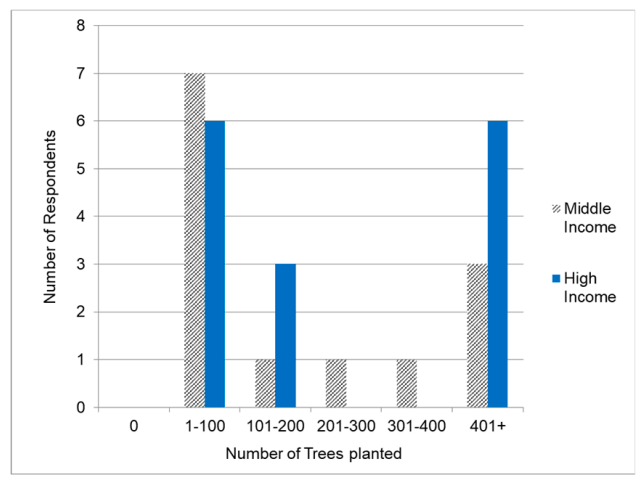

(a)

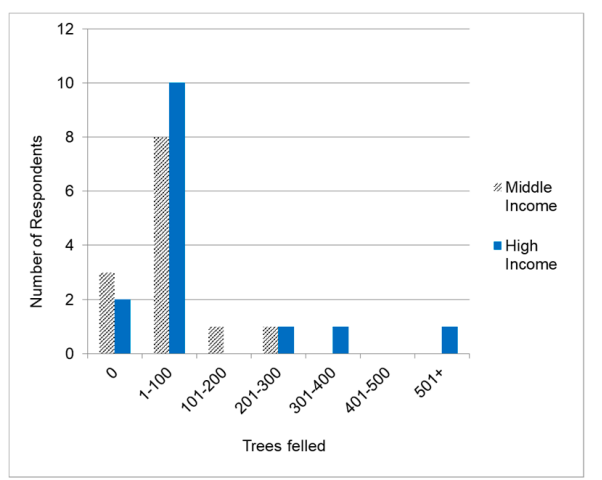

(b)

Figure 4. ToF responses separated by income groups: (a) ToFs established; (b) harvesting of ToFs.

Moreover, results indicate that many respondents have felled between 1-100 ToFs, as shown in Figure $4 \mathrm{~b}$. However, respondents from the rich category appear to have felled more in-view of the frequency of their occurrence in the tree categories felled as indicated in Figure $4 \mathrm{~b}$. Overall, more trees were planted than felled in the period under study. Also, ToFs management between the years 2009-2019 may have improved the incomes of the respondents more or less equally by at least 1-10\%, as shown in Figure 5.

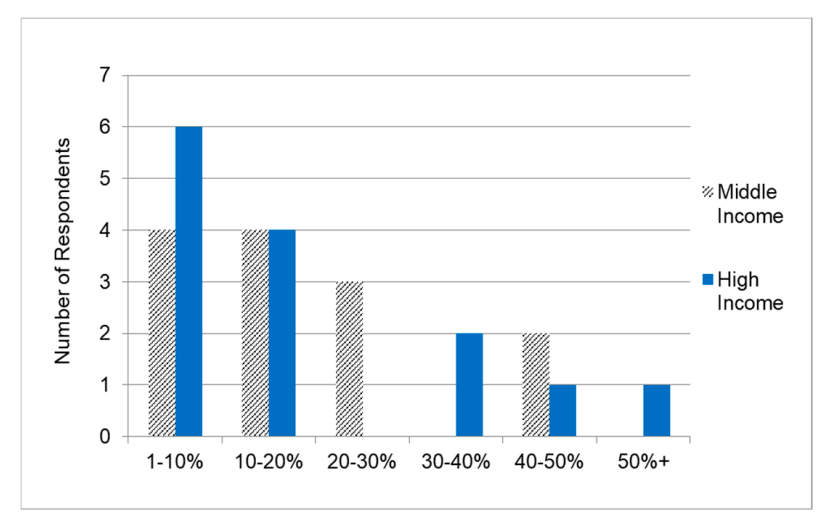

Figure 5. The proportion of improved household income from tree sales. 


\subsection{The Challenges Facing ToFs}

ToFs establishment has had several challenges. Most respondents have reported strong winds as the leading cause of tree damage followed by drought and electricity power line installation, as shown in Figure 6a below. Surprisingly, both the middle- and affluent-income groups have done nothing about these tree damages despite acknowledging that trees were important for income and environmental protection. Some tree damage incidences were reported to the police, while some were reported to the chief, as shown in Figure 6 b.

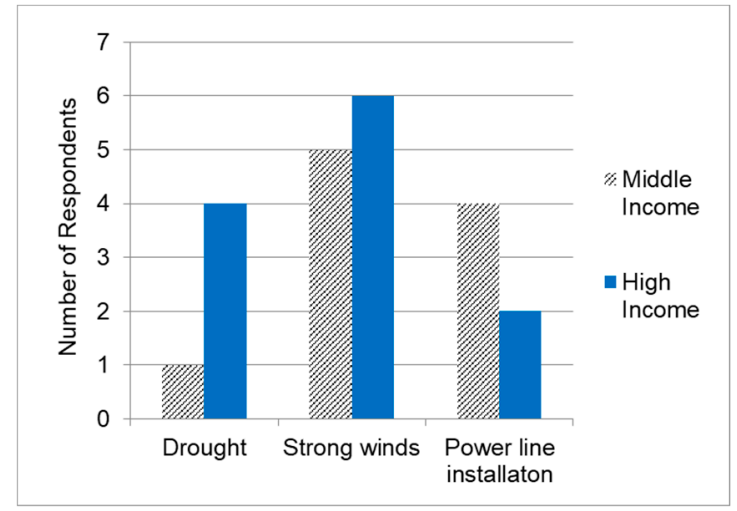

(a)

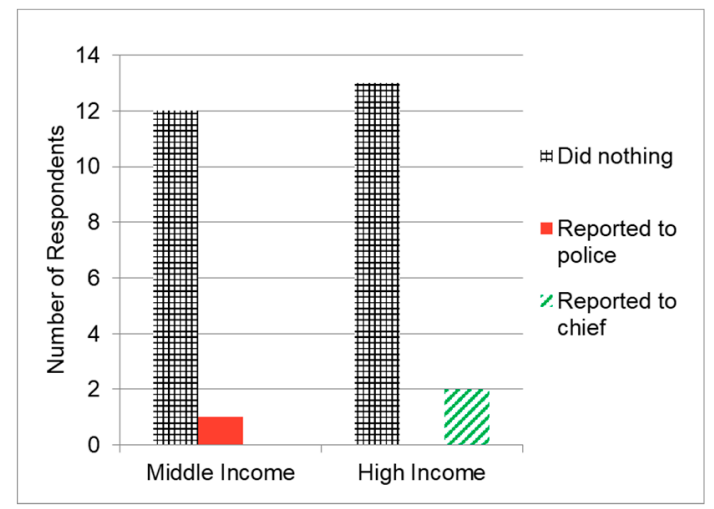

(b)

Figure 6. Damage responses separated by income groups: (a) Causes of damage to ToFs; (b) tree damage management.

Other challenges identified from the income groups include the highly technical nature of Farm Forestry Rules, 2009, lack of consolidated tree planting manuals and guidelines, limited professional tree growing advice, few tree planting self-help groups and limited awareness, lack of ToFs management plans and felling plans, lack of private forest registration by the government, limited awareness on the rules, and lack of compensation for damaged trees. Respondents have indicated that they would gladly recommend tree growing to other landowners for climate change mitigation, as shown in Figure 7.

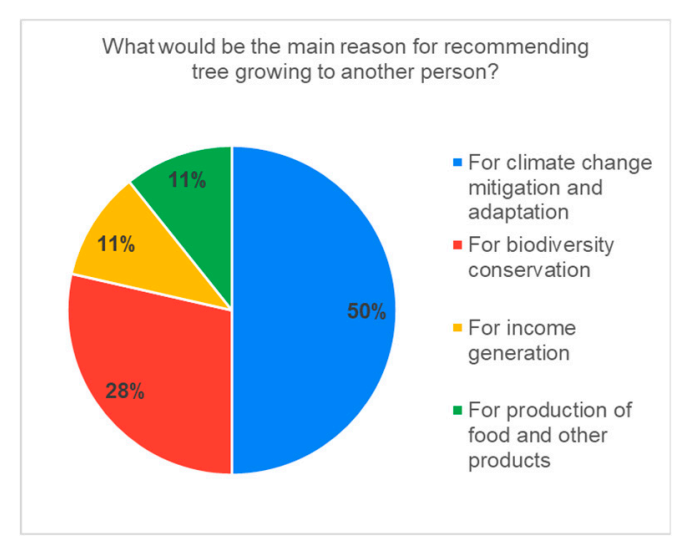

Figure 7. Reasons for recommending ToFs.

\section{Discussion and Conclusions}

Discourses on reviewing forest policies towards sustainable development have dominated conservation circles in the past few decades with an increasing tendency towards enhancing the contribution of ToFs [20-29]. Kenya has also experienced similar forest policy shift with attention now focused on realizing their full potential of ToFs. However, the main factors driving this adoption seem to understudy, focusing less on policy factors. This study addressed this gap by investigating 
policy factors with the particular bias on the Farm Forestry Rule, which expressly provides that every landowner in the country should maintain $10 \%$ forest cover on their land.

Review results indicate that the rules are quite progressive and intended to boost the landowners' household needs [11]. At the national level, the objectives of the rules are also in harmony with other related policies, such as the Forest Conservation and Management Act, 2016, EMCA, 1999, the Climate Change Act, 2016, and the draft forest policy 2014. These rules are inclined to hasten the achievement of Kenya's commitments to many international obligations and Sustainable Development Goals.

\subsection{The Impact of Rules on ToFs, Livelihoods and Sustainable Development}

Even though at the national level, there are limited studies on how the policy provisions and rules may have transformed ToFs on agricultural land. Early lessons from the Lugari sub-county shows that in the period 2009-2019, landowners may have embraced ToFs because they have embraced a tree planting culture and the importance of trees for household needs and livelihoods. Results show that in the period 2009-2019, ToFs have had some positive social, economic, and environmental impacts. Figure 5 shows improved incomes resulting from the management of ToFs. For both high and middle expenditure groups, most respondents improved their incomes by at least $1-10 \%$. However, the high-income group registered a slightly higher number of respondents compared to the middle-income expenditure group. Also, the high income-expenditure group seems to have harvested more tree than the middle income-expenditure group. These results seem to agree with data, which suggested that the level of income increases the amount of wood consumption [6]. Moreover, these results agree with propositions in favor of the centrality of ToFs in enhancing human survivability [30].

Besides, around $22 \%$ of the overall respondents are members of a self-help group that deals with tree growing. Respondents have indicated that some groups were formed even before the enactment of the Farm Forestry rules, 2009. This result is an essential first step towards the formation of out-grower schemes that will promote farmer-to-farmer forestry extension services besides acting as a platform for capacity building and collective bargaining.

There are two national tree growing associations in Kenya. For a western region where the Lugari sub-county belongs, there is Western Tree Planters Association with offices in Webuye town. These associations and groups are the catalysts for achieving what Anyonge and Roshetko [1] reported as increasing contractual (corporate-smallholder partnerships) arrangements amongst small-holders tree growers as organizations to promote marketing of ToFs products.

Moreover, results indicate that there were many instances of tree planting and harvesting, as shown in Figure 4a,b. Overall, Eucalyptus spp. (61\%) was the most favored tree species followed by Grevillea spp. (25\%), then Cypress and Jacaranda spp. Line boundary planting was the most common practice for raising ToFs. The preference for Eucalyptus spp. may be attributed to their fast growth characteristic, which translates to early incomes for landowners.

Additionally, besides the ready market, Eucalyptus spp. planting guidelines are readily available even online, and the trees are extensively grown in government forests surrounding the study area. However, in-view of tree damages reported by respondents, there may be the need to diversify the tree species being grown by landowners. One option could be to explore the possibilities of growing sandalwood, which fetches good returns in the international markets, as indicated by Kamondo et al. [14].

Interestingly, all study respondents $(100 \%)$ have expressed willingness to promote ToFs to other landowners to conserve biodiversity $(29.6 \%)$ and enhance resilience against the impacts of climate change $(48.1 \%)$ representing a total of over $77 \%$, as shown in Figure 7 . It provides favorable conditions for implementing the Farm Forestry Rules of 2009, given the goodwill and similarity in objectives pursued. Further, this paper considers that the high level of willingness to recommend ToFs to other landowners for environmental benefits may be attributed to the high level of education amongst respondents. There is also a need to investigate further the impact of other variables, such as gender, income-expenditure level, and age of respondents on harvesting and establishment of ToFs based on 
actual farm visits and tree inventory data [13]. In addition, the favorable climatic conditions in the sub-county identified by ROK [18] may also be encouraging tree planting activities.

Nevertheless, the most interesting finding in this study, which appears to contradict widely held opinion in the country, shows that respondents are increasingly adopting ToFs despite their relatively younger age of between 18-35 years. It contrasts with findings by Wafuke [12], who found that the adoption of ToFs increases with increase in the age of landowners. This study attributes this adoption to the higher education level amongst study respondents. Moreover, despite the uncertainty of data, the increased tree planting may have resulted from the logging moratorium of 2018, which may have created increased timber demand that was being responded to by tree growers. Under similar circumstances, Muthomi and Vandenabeele [31] had reported that tree growing activities increased on farms as landowners anticipated high returns. However, Nkamleu and Manyong [32] cautions that outcomes from such variables, such as logging bans may not be generalized because of the uniqueness of practices employed by landowners. Nonetheless, this paper submits that the observed livelihood improvements resulting from ToFs are in agreement with findings on ToFs by many researchers $[2,9,12,13,30,33-37]$.

\subsection{Adequacy of Farm Forestry Rules 2009}

ToFs owners have experienced many challenges, mainly due to inadequacies of the Farm Forestry Rules, 2009, and other policy documents. There are inconsistencies arise from failure to clearly define the terms tree cover and forest cover in the Constitution 2010. For instance, despite the rules having been reviewed in the year 2012, article two of the rules on application under page A11-194 states that "these rules shall apply for the purposes of promoting and maintaining farm forest cover of at least 10 percent of every agricultural landholding and to preserve and sustain the environment in combating climate change and global warming." Whereas, article 4 on objectives and purpose of the rules under page A11-194 states that "the objective and purpose of these rules is to promote the establishment and sustainable management of farm forestry to maintain a compulsory farm tree cover of at least 10 percent of any agricultural landholding."

In this paper, the term forest cover has its origin from the term a forest, which can be defined variously. According to FAO, a forest refers to land spanning more than 0.5 hectares with trees higher than $5 \mathrm{~m}$ and a canopy cover of more than 10 percent, or trees able to reach these thresholds in situ [38]. FAO elaborates that this definition does not include land that is predominantly under agricultural or urban land use. Whereas, in the Forest Conservation and Management Act, 2016, a forest refers to land which is declared or registered as a forest, or woody vegetation growing nearby in an area of over $0.5 \mathrm{ha}$, including a forest in the process of establishment, woodlands, thickets. However, MENR has criticized the definition by the Forest Conservation and Management Act, 2016, as vague and subject to various interpretations because it does not specify the height of trees and the size of tree canopy examined.

Further, MENR reported that there is no systemic data collection to assess the tree cover in the country and monitor the country's performance towards achieving the target set by the Constitution of 2010. Unfortunately, the terms forest cover and tree cover are numerously cited. Almost interchangeably in the Farm Forestry Rule, 2009 in article 2, 4, 6, 7, and 10 without being defined in article 3 under interpretations to any definition. This result represents a significant inconsistency that could undermine the monitoring and evaluation of rule and related policy documents during implementation. In addition, besides landowners, government officials themselves may be confused over which definition to apply in which situation. Therefore, streamlining the existing legislation and rules in relation to ToFs management is required. This paper agrees with MENR findings on the lack of a tree cover inventory protocol in Kenya and calls upon stakeholders to establish this system in order to improve the preference of ToFs by agricultural landholders.

Results also indicate that rule implementation requires that the management of ToFs be monitored by the inspector, who is defined in the document as the District Agricultural Officer (DAO). In 
contrast, harvesting, processing, movement of ToFs will be subject to the procedures of the Forest Conservation and Management Act, 2016. This paper considers that without well-known standard operating procedures that are understood by both the landowner, inspector, and the officer-in-charge of implementing the forest law, in the future, this may result in conflicting extension and administrative advice on ToFs management as reported by Anyonge and Roshetko [1]. It is based on such inconsistencies and grey areas that this study result claims that the Farm Forestry Rule has remained widely unpopular amongst landowners in the Lugari sub-county.

ToFs owners in the Lugari sub-county are also experiencing losses, due to tree damage, but they would wish to continue cultivating trees, as shown in Figure 7. Even though this study did not undertake an inventory to determine the amount of damage, respondents indicated that they had experienced tree damage from strong winds, especially in December and January, power line installation works, and drought (Figure 6a) affecting incomes. However, what should worry about many conservationists are the damage management strategies employed by landowners. From Figure 6b, most landowners from both middle and high-income groups did nothing to address tree damage! Nevertheless, the Farm Forestry rules, 2009 in article 11, are clear on compensation after evaluations by the District Agricultural Committee. The article 11 (3) and (4) are apparent, they state "(3) the Central Agricultural Board (CAB) shall prepare and publish farm tree compensation guidelines for use in assessing compensation rates. (4) The Central Agricultural Board shall review the farm tree compensation guidelines for use in assessing compensation rates after every five years from the date of its publication."

Besides compensation from $\mathrm{CAB}$, landowners could consider having an insurance policy for their trees where they can be compensated in-case of such losses as suggested by Sikuku et al. [13]. There may be a need to carry out a study on the feasibility of this option in order to provide tree growers with adequate information on providers of such cover. Nevertheless, many other incidences seem to suggest the unpopularity of the Farm Forestry Rule, 2009. For instance, for those respondents that are not organized into groups, they claim that no one has approached them for facilitating self-help group activities, yet the rule exists for this purpose. Other challenges identified across the income groups that seem to indicate the rule unpopularity include an acute shortage of professional advice on the establishment and management of ToFs in the sub-county. For instance, most landowners with ToFs do not have management plans and have no access to tree planting manuals. Coincidentally, these challenges are similar to challenges presented in previous studies in the Lugari sub-county $[12,13]$ and global cases [39,40]. However, the challenge of lacking tree planting manuals may be debatable because the government has provided many guidelines, for example, the Eucalyptus spp. and sandalwood guidelines which are available online and could be used to boost farm incomes. The only challenge that may significantly inhibit sandalwood adoption on farms is the three permits required to grow it [41]. Given the three permits required for sandalwood, this finding seems to agree with Anyonge and Roshetko [1], who found that sometimes the application of multiple policies and laws (institutions) affect sustainable management of ToFs. Moreover, this paper notes the identified tree planting manuals (Eucalyptus spp. and sandalwood) exist independently in separate documents this may present a challenge to landowners who may prefer to have their information in one booklet or document.

Surprisingly, the impact of the logging moratorium imposed in the country on 28th February 2018 on all state and community forests did not feature in this survey as a challenge to the sustainability of ToFs. However, this paper submits a lack of ToFs data, due to lack of inventory protocols in the country and failure to implement the Farm Forestry Rules, 2009. The current logging moratorium could be exacerbating the un-sustainable management of ToFs by encouraging more trees cutting on farms as reported, including the case of Nyandarua county in central Kenya [42,43].

This paper concludes that ToFs have had some positive impacts on landowners. However, given challenges experienced, especially unpopularity of the Agriculture (Farm Forestry) rules of 2009 and the glaring non-implementation, these positive impacts cannot be directly attributed to a response to the Farm Forestry Rules of 2009. There may be the need for a study to investigate other internal 
and external factors beyond the farm forestry rules that could be influencing ToFs management, for instance, the impact of the logging moratorium of 2018, the role of stakeholders amongst others need to be investigated. This paper calls for addressing the definitional inconsistencies in the rules, transcribing the rule in other languages, more awareness creation on the rules, and developing tree inventory protocols in order to create an impact on landowners. At the same time, implementing these recommendations will help minimize the impact of the uncertainty of data that was discussed previously in this paper. Additionally, the study showed a lack of sensitivity analysis, which could compare current and future scenarios to provide a deeper understating of the impact of legislation on the sustainability of farm forests in Kenya, and it is recommended to conduct soon.

Author Contributions: Conceptualization, S.N.C. and C.Y.; methodology, S.N.C.; formal analysis, S.N.C.; investigation, S.N.C.; writing-original draft preparation, S.N.C.; writing-review and editing, J.P. and C.Y.; visualization, J.P.; supervision, C.Y. All authors have read and agreed to the published version of the manuscript.

Funding: This research was funded by the University of Seoul grant number [201805031013].

Acknowledgments: This work was supported by the 2018 Research Fund of the University of Seoul.

Conflicts of Interest: The authors declare no conflict of interest.

\section{References}

1. Anyonge, C.H.; Roshetko, J.M. Farm-level timber production: Orienting farmers towards the market. Unasylva 2003, 54, 48-56.

2. Scherr, S.J. Building opportunities for small-farm agroforestry to supply domestic wood markets in developing countries. Agrofor. Syst. 2004, 61, 357-370.

3. Simons, A.J.; Leakey, R.R.B. Tree domestication in tropical agroforestry. New Vistas Agrofor. 2004, 61, $167-181$.

4. Luukkanen, O. Kenya forestry master plan. Sustain. For. Chall. Dev. Ctries. 1996, 10, 359-369.

5. Kenya Wildlife Service. Available online: www.kws.go.ke (accessed on 18 October 2019).

6. Ministry of Environment and Natural Resources. Available online: www.environment.go.ke (accessed on 18 October 2019).

7. The Draft Forest Policy 2014. Available online: www.kenyalaw.org (accessed on 18 October 2019).

8. Dewees, P. Trees and Farm Boundaries: Farm Forestry, Land Tenure and Reform in Kenya. J. Int. Afr. Inst. 1995, 65, 217-235. [CrossRef]

9. Nyangena, W. Social determinants of soil and water conservation in rural Kenya. Environ. Dev. Sustain. 2008, 10, 745-767. [CrossRef]

10. Kenya Forest Service. Forest Status Report; Kenya Forest Service: Nairobi, Kenya, 2018; Available online: www.kenyaforestservice.org (accessed on 18 October 2019).

11. Rotich, J.; Sirmah, P.; Edward, M.; Odwori, P. Agroforestry trees in Kapsaret, Kenya: Socio-economic perspectives influencing availability, preference and utilization. Int. J. Agrofor. Silvic. 2017, 5, 315-325.

12. Wafuke, S. Adoption of Agroforestry Technologies among Small Scale Farmers in Nzoia Location, Lugari District, Kenya. Ph.D. Thesis, Egerton University, Nakuru, Kenya, 2012.

13. Sikuku, F.O.; Apudo, M.G.; Ototo, G.O. Factors influencing development of farm forestry in Lugari district, Kakamega county, western Kenya. J. Agric. Vet. Sci. 2014, 7, 6-13. [CrossRef]

14. Kamondo, B.; Giathi, G.; Osore, C.; Machua, J.; Kagunyu, L.; Wafula, A.; Bala, P.; Njuguna, J.; Wakori, S.; Maingi, F.; et al. Growing of East African Sandalwood. Guidelines for Tree Growers; KEFRI: Nairobi, Kenya, 2014.

15. World Bank. Poverty and Inequality. Available online: http://datatopics.worldbank.org/world-developmentindicators/themes/poverty-and-inequality.html (accessed on 18 October 2019).

16. Jolliffe, D.; Prydz, E.B. Estimating International Poverty Lines from Comparable National Thresholds; The World Bank: Washington, DC, USA, 2016.

17. Ghosh, M.; Sinha, B. Impact of forest policies on timber production in India: A review. Nat. Resour. Forum 2016, 40, 62-76. [CrossRef]

18. Government of Kenya, Lugari District (2002-2008) Development Plan; Government Press: Nairobi, Kenya, 2002. 
19. Wanyonyi, R.W. Impact of Human Population on Land Degradation in Former Lugari District, Kakamega County, Kenya. MSc Thesis, Kenyatta University, Nairobi, Kenya, 2012.

20. Petersen, L.; Sandhövel, A. Forestry policy reform and the role of incentives in Tanzania. For. Policy Econ. 2001, 2, 39-55. [CrossRef]

21. Gautam, A.P.; Shivakoti, G.P.; Webb, E.L. A review of forest policies, institutions and changes in the resource condition in Nepal. Int. For. Rev. 2004, 6, 136-148. [CrossRef]

22. Wang, S.; Kooten, G.C.; Wilson, B. Mosaic of Reform: Forest policy in post 1978-China. For. Policy Econ. 2004, 6, 71-83. [CrossRef]

23. Diete, T.; Ferguson, I.; MacLaren, D. Log export restrictions and trade policies in the Philippines: Bane or blessing to sustainable forest management? For. Policy Econ. 2005, 7, 187-198. [CrossRef]

24. Spies, T.A.; Johnson, K.N.; Burnett, K.M.; Ohmann, J.L.; McComb, B.C.; Reeves, G.H.; Garber-Yonts, B. Cumulative ecological and socioeconomic effects of forest policies in coastal Oregon. Ecol. Appl. 2007, 17, 5-17. [CrossRef]

25. Petkova, E.; Larson, A.; Pacheco, P. Forest governance, decentralization and REDD+ in Latin America. Forests 2010, 1, 250-254. [CrossRef]

26. Kotilainen, J.; Rytteri, T. Transformation of forest policy regimes in Finland since the 19th century. J. Hist. Geogr. 2011, 37, 429-439. [CrossRef]

27. Redo, D.; Millington, A.C.; Hindery, D. Deforestation dynamics and policy changes in Bolivia's post-neoliberal era. Land Use Policy 2011, 28, 227-241. [CrossRef]

28. Amiraslani, F.; Dragovich, D. Forest management policies and oil wealth in I ran over the last century: A review. Nat. Resour. Forum 2013, 37, 167-176. [CrossRef]

29. De Jong, W.; Cano, W.; Zenteno, M.; Soriano, M. The legally allowable versus the informally practicable in Bolivia's domestic timber market. For. Policy Econ. 2014, 48, 46-54. [CrossRef]

30. Leakey, R.R.; Tomich, T.P. Domestication of tropical trees: From biology to economics and policy. Sustain. Agric. Syst. 1999, 14, 325-344.

31. Muthomi, M.; Vandenabeele, J. The Future of Kenya's Gazetted Forest Plantations. Better Globe Media. Available online: https://www.betterglobemedia.com/public/blog/304/the-future-of-kenyas-gazetted-forestplantations (accessed on 18 October 2019).

32. Nkamleu, G.B.; Manyong, V.M. Factors affecting the adoption of agroforestry practices by farmers in Cameroon. Small Scale For. Econ. Manag. Policy. 2005, 4, 135-148. [CrossRef]

33. Muchiri, M.N.; Pukkala, T.; Miina, J. Modelling trees' effect on maize in the Grevillea Robusta+maize systems in Central Kenya. Agrofor. Syst. 2002, 55, 113-123. [CrossRef]

34. ICRAF. International Centre for Research in Agroforestry; Annual Report; ICRAF: Nairobi, Kenya, 1993; pp. 98-101.

35. Jagger, P.; Pender, J. The role of trees for sustainable management of less-favored lands: The case of eucalyptus in Ethiopia. For. Policy Econ. 2003, 5, 83-95. [CrossRef]

36. Wasiq, M.; Ahmad, M. Sustaining Forests: A Development Strategy; The World Bank: Washington, DC, USA, 2004.

37. Rotich, B.; Chepkemboi, M. Status of farm forestry in Tarakwa Location, Uasin Gishu county, Kenya. Int. J. Sci. Res. 2017, 6, 2035-2038.

38. Food and Agriculture Organization of the United Nations. Global Forest Resources Assessment 2000: Main Report; Food and Agriculture Organization of the United Nations: Roma, Italy, 2001.

39. Clay, D.C. Fighting an Upzhill Battle: Population Pressure and Declining Land Productivity in Rwanda; No. 1096-2016-88372; Michigan State University: East Lansing, MI, USA, 1996.

40. Babatunde, R.; Oyatoye, E. Food security and marketing problems in Nigeria: The case of maize marketing in Kwara State. In Proceedings of the International Conference on Research for Development in Agricultural Forestry, Food and Natural Resources Management, Stuttgart-Hohenheim, Germany, 11-13 October 2005.

41. Business Daily. Researcher Entices Farmers with Lucrative Sandalwood in Conservation Drive. Available online: https:/www.businessdailyafrica.com/magazines/sandalwood-in-conservation-drive/ 1248928-3403700-c9vtbaz/index.html (accessed on 18 October 2019). 
42. Business Daily. Logging Ban Hits Construction Sector Hard as Costs Double. Available online: https://www.businessdailyafrica.com/markets/commodities/Logging-ban-hits-construction-sectorhard-as-costs-double/3815530-4368166-aqn00pz/index.html (accessed on 18 October 2019).

43. Daily Nation. Logging Ban Derails Forest Cover Goal as Traders Go for Homes. Available online: https://www. nation.co.ke/news/Logging-ban-derails-forest-cover-dream/1056-4915202-6h6472/index.html (accessed on 18 October 2019).

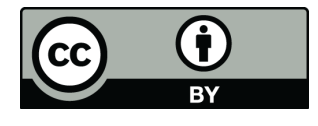

(C) 2019 by the authors. Licensee MDPI, Basel, Switzerland. This article is an open access article distributed under the terms and conditions of the Creative Commons Attribution (CC BY) license (http://creativecommons.org/licenses/by/4.0/). 